Available online on 15.01.2020 at http://jddtonline.info
Open Access to Pharmaceutical and Medical Research
unrestricted non-commercial use, provided the original work is properly cited

Open $\odot$ Access

Review Article

\title{
Current Approaches on Gastroretentive Drug Delivery systems
}

\author{
Aniket Uttam Pund ${ }^{1}$, Raosaheb Sopanrao Shendge 2*, Ajinkya Kailas Pote ${ }^{3}$ \\ ${ }^{1}$ Research scholar, Department of Pharmaceutics (PG), Sanjivani College of Pharmaceutical Education and Research, Kopargaon, Maharashtra, \\ India \\ 2 Professor, Department of Pharmaceutics (PG), Sanjivani College of Pharmaceutical Education and Research, Kopargaon, Maharashtra, India \\ ${ }^{3}$ Research scholar, Department of Pharmaceutics (PG), Sanjivani College of Pharmaceutical Education and Research, Kopargaon, Maharashtra, \\ India
}

\begin{abstract}
Over recent years, there have been many efforts to develop the absorption rate of medications and the therapeutic efficacy of oral dosage types. GRDDS for strengthen the pharmacological effects of drugs with a small uptake site, are unbalanced at pH greater than 7, are dissolved under acidic region, and are effective local region in the stomach. The gastro retentive systems that have the different evaluation parameter that according to the dosage forms. There are many criteria for the choosing of the drug used in the gastro-retardant systems as the drug should be sparingly stable, it should be compatible with the gastric region, and narrow absorption. In this review, we have summarized the information related to the various approaches for enhancing and prolonging of the dosage forms in the stomach for their extended-release of action. Also talking about the many natural and synthetic polymers is used in the formulation with their different grade and their ratio that affects on the release action. The many scientist and inventors have increased their interest in developing the novel dosage forms and they staying in the stomach for showing the prolonged period action. We have also discussed the novel technology are involved in the gastric retention many companies has been developed the polymer grades for using it in the formulation for showing the retention action.
\end{abstract}

Keywords: Introduction, Approaches, Novel technologies, Polymer used in floating systems.

Article Info: Received 22 Oct 2019; $\quad$ Review Completed 09 Dec 2019; $\quad$ Accepted 17 Dec 2019; Available online 15 Jan 2020

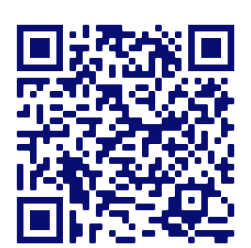

Cite this article as:

Pund AU, Shendge RS, Pote AK, Current Approaches on Gastroretentive Drug Delivery systems, Journal of Drug Delivery and Therapeutics. 2020; 10(1):139-146 http://dx.doi.org/10.22270/jddt.v10i1.3803

*Address for Correspondence:

Education and Research, Kopargaon, Maharashtra, India

\section{INTRODUCTION}

The oral route is best path for the drug administration for single-dose systems and it is easy for administration and cost-effective for developing a single dos controlled release or extended or sustained release dosage form the extensive research has been performed for making the better patient compliance and avoidance of repeated administration of the drug the highly soluble drug at acidic $\mathrm{pH}$ condition and lower solubility at pH higher than 7 resulted as a lower absorption window drug from intestine. The basic advantages of GRDDS are to enhance the bioavailability and they having sitespecific drug delivery for treating GI disorder when the drug bioavailability is increased then decreasing the dosing repetition and ultimately the minimizing GI disorder the disadvantages of the GRDDS is incompatible with those medications that irritate the gastric mucosa compared to conventional dosage form.[1] Formulation is to standing in the stomach for an indefinite time by providing a product material to the top part of the GI tract
There is the various method for increasing the gastric retention time in the stomach such as floating systems which including the low density in that gas generating system, swelling systems in these systems the dosage form are floated in the gastric fluid due to density of the components is should be less than the density of the stomach.[2] In the bio adhesive system the dosage form adheres to the mucosal surface there are many theories are involved in these systems in the high-density system dosage form they remain in the distal section of the stomach because of the mass of dosage form are higher than gastric fluid. In the super porous hydrogel system, the dosage form is swelled due to water uptake through the porous by a capillary wetting mechanism. In the raft forming systems contains polymers they swell and form the in situ gel layer and they are floated above the gastric fluid called raft forming systems. In the expandable techniques, systems is swell and unfold and it occurs by diffusion.[4] 


\section{Anatomy of stomach}

The most dilated of the gastrointestinal tract is the stomach and it is positioned between the the esophagus and small intestine. The pyloric sphincter governs the opening of stomach in the duodenum. The stomach can be classified into four anatomical part namely; fundus, body, antrum, pylorus.[5]

\section{Composition of gastric content}

The stomach has a capacity is about 1.12-1.5 L, normal stomach possess the J shape. The larger most part of the stomach is the fundus area accounting for $60-80 \%$ of total mucosal surface. The bottom half of the fundus zone is segregated from the pylorus by the lower curvature angle forms known as Incisura angularis. the interface of pyloric and fundus region is not sharply detached and its also referred to as the transitional zone the circular fiber of pyloric sphincter guarded the backflow of small intestine contents into the stomach. Form total mucosal region contains $15 \%$ pyloric area and partition to two components pyloric antrum. Which would be relatively abbreviated broader, closer chamber and the pyloric canal the narrow tubular passage ends in the pyloric sphincter about $3 \mathrm{~cm}$ long. The $\mathrm{pH}$ of the napping stomach in young adults ranges from 1.7 to 1.3 in the elder one. The typical stomach secretes approximately $3 \mathrm{~L}$ of fluid every 24 hours and these fluids consists of primarily mucus, lipase enzyme, also pepsinogen, acid and intrinsic factors which mostly gastric secretion it includes,

1.Parietal cell produces acids, Which keeps the $\mathrm{pH}$ of the stomach in the fasted state from 1 to 3.5

2.Gastrin hormone, Which is an effective modulator of the development of gastric acid

3. Pepsins that from the peptic cells created in the form of their pepsinogen precursor 4.Mucus, initiated from the surface mucosal cells and lines the gastric mucosa[6, 7]

\section{Function of stomach}

Primary part of the stomach is fundus, the larger part of the stomach is body and antrum. The storage is done by fundus and body, whereas the function of the antrum is grinding and sieving of food. the stomach consist of mucosa does not contain gastric pits[8]

\section{Migrating myoelectric complex (MMC) cycle}

In the both fasting and fed states gastric emptying are obtained. Nevertheless, the motility pattern varies. markedly in the two condition in the fasted condition it is characterized by an inter-digestive 4 phase as shown on figure 1.

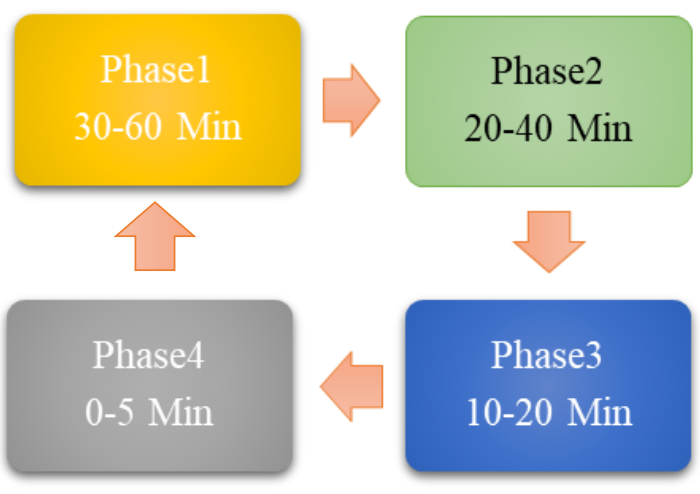

Figure 1: Phase cycle

Phase1.It is a relatively inactive 40-60 minute period with only occasional contractions. Phase2.Incresing numbers of contractions are present in phase2, which has a similar duration to phase 1

Phase3.This is characterized by strong peristaltic contractions after opening the base of pylorus and clears the stomach of any residual material.

Phase4. This is a less period of transition among powerful action of phase 3 and phase 1 .The process repeats every 2 hours until the meal is eaten and fed or motility starts

\section{Advantages}

1.Increase the intestinal absorption

2.Increase drug activity

3.Formulate continue release drug delivery

4.Providing predertermined activity

5. Deceased product concentration changes

6. Enhanced receptor activation selectivity $[9,10]$

\section{Approaches for Gastroretentive Drug Delivery System}

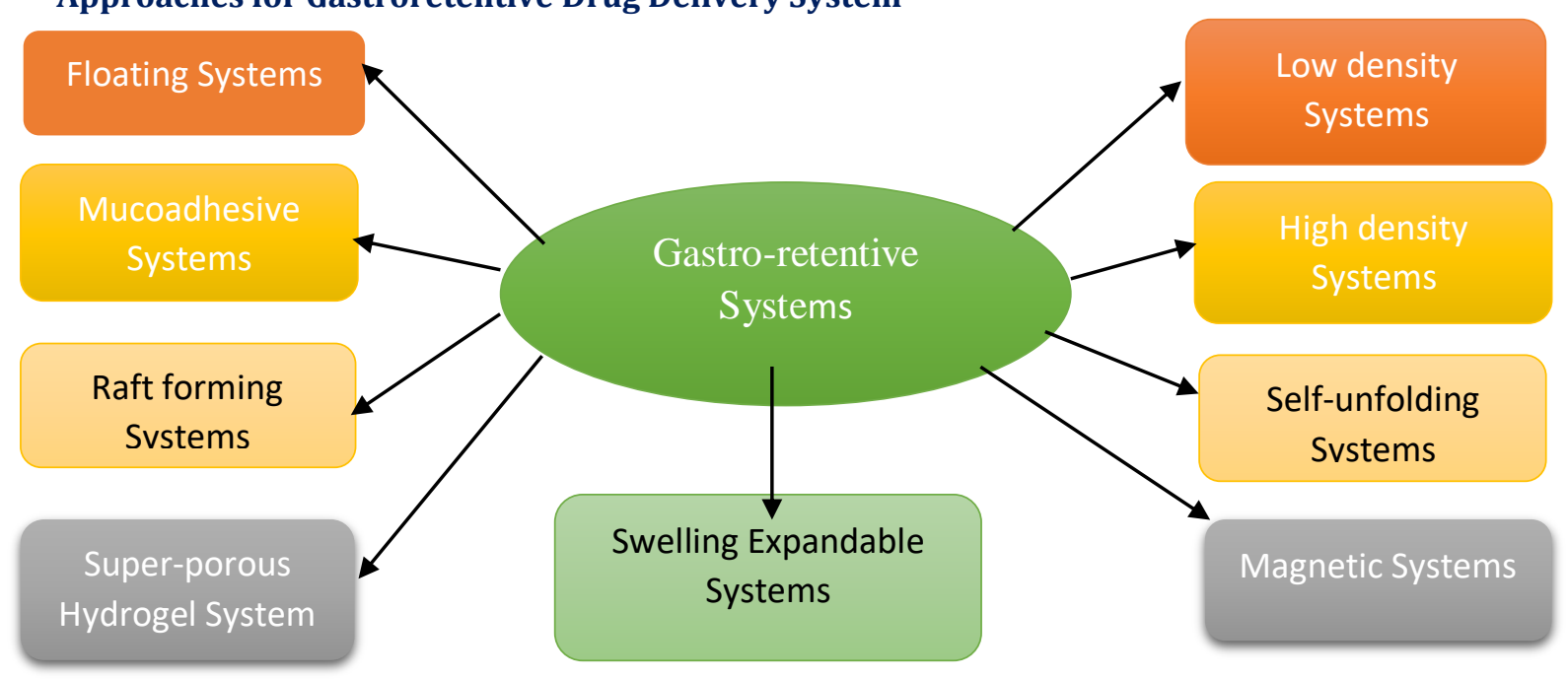




\section{LOW-DENSITY SYSTEMS}

This systems was firstly introduced by J.DAVIS in 1968. it is also said as hydro dynamically balanced systems for floating the bulk density should be lesser than $(1.004 \mathrm{~g} / \mathrm{cm})[11,12]$

Due to this, they allow to floated a dosage form for a lengthened time in the stomach

They are major approaches to reaching a longer gastric retention time and shows higher drug bioavailability $[13,14]$

Low-density systems or floating systems are of the two types as, [15]

1. Non-effervescent systems

\section{Effervescent systems}

\section{(1).Non-effervescent floating drug delivery systems}

It was firstly described by Sheth PR and Tossounlan J in 1984 the main advantages of non-effervescent systems is the stability of acid or base labile drug gastric pH not affected floating lag time.

The tablet was designed with a mixture of optimized solid dispersion and action retardant polymers/swellable polymers such as xantham gum and polyethylene oxide in the hydrodynamically balanced system contains drugs with gel-forming agent or swellable cellulose type hydrocolloids, polysaccharides and matrix-forming. Polymers help prolong the staying time of GI and improve the absorption of drugs. Microporous compartments systems consisting of drug encapsulation reservoirs inside pores in microporous compartment. The floatation chamber of trapped air allows the system to buoyance over gastric material in the stomach.

\section{(2).Effervescent floating drug delivery systems}

In these preparation including a release retardant polymers, ethylcellulose, eudragit L100,xantham gum, polyethylene oxide(PEO)N12K.[17] In that formulation the gas generating agent. Makes better the buoyancy of the tablet in gastrofloating systems consists hydrophilic polymers combination. Nonetheless, no systematic study has yet been carried out to investigate the effect of sodium bicarbonate on drug release kinetics, so it is important to investigate its impact in the effervescent process on drug release kinetics of higher water-soluble drugs.The gas entrapped membrane was usually observed during storage leading to failures in floating and sustained release these can be overcome by the using glyceryl monostearate and talc as an anti-tacking agent.[18, 19] As shown in Figure 2.

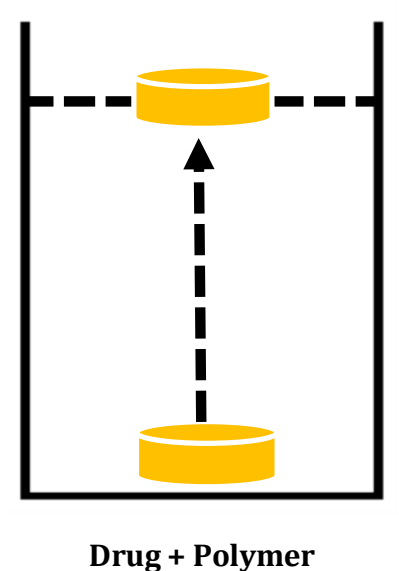

Figure 2: Effervescent systems

\section{(i).Gas generating systems}

The effervescent reaction among carbonate/bicarbonate salts, citric/tartic acid, $\mathrm{CO} 2$ is released in presence of water when the formulation is put in the beaker it will sink with a production of gas it rises up and floats. [20]

\section{(ii).Volatile liquid containing system}

It consists of the liquid in inflatable chamber like ether that produces gas at body temperature to causing the inflation of the chamber in the stomach. This inflatable chamber holds a pool of medicines stored in a capsule of gelatin. The capsule disperses the drug reservoir after ingestion together with the inflatable. due to this forming of gas bubbles of $\mathrm{CO} 2$ by incorporation of carbonates or bicarbonates, by contact with gastric region.[21]

\section{(iii).Raft forming systems}

In this process, a viscous gel containing trapped carbon dioxide bubbles on contact with gastric fluid is created by carbonates or bicarbonates. Formulation often typically contains antacid such as aluminum hydroxide or calcium carbonate to minimize gastric acidity. They create a layer on upper of gastric fluids which are often used in GI treatment as with water.[22]

\section{HIGH DENSITY SYSTEM}

The gastric fluid density is the same as water such as $1.004 \mathrm{~g} / \mathrm{ml}$ the system are retained in the stomach is possible when the density of systems is equal to $3 \mathrm{~g} / \mathrm{ml}$ and they enable the system are withstand peristaltic movements in the stomach. By using titanium dioxide, iron powder, zinc oxide, barium sulfate they higher the retention period.[23, 24] as shown in Figure 3.

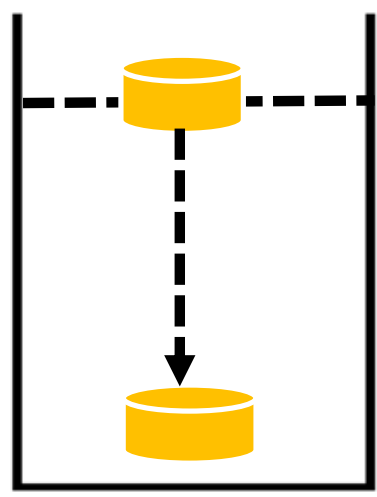

\section{Drug + Polymer}

Figure 3: High Density system

\section{EXPANDING SYSTEM}

For the past 3 decades, expandable gastrointestinal retentive dosage forms have been produced. They were actually designed for potential medical veterinary use, but a letter to boost drug therapy for humans was changed. The expandable GRDFs are usually a small configuration depends, which enables for a convenient expanded oral intake in the stomach and thus prohibits the travels through the pyloric sphincter. Dissolution of the polymers and thus maintain the physical integrity of the dosage form. Such cross-linking prevent the polymers from dissolving and thus preserve the physical properties of dosage type. A high degree of cross-linking delays the system's swelling ability to maintain its physical integrity for extended periods of time.[25] as shown in Figure 4. 


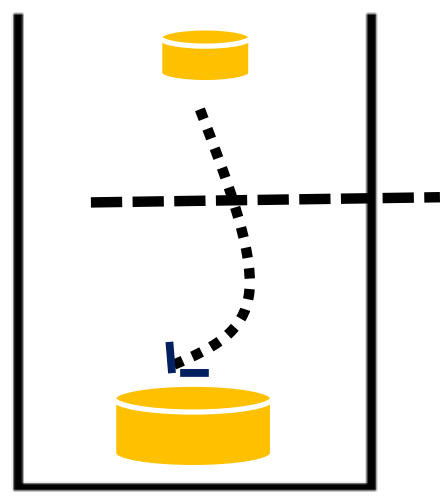

Drug + Swellable Polymer

Figure 4: Expanding system

\section{BIO ADHESIVE SYSTEMS}

Bioadhesive means adhesion to the biological surface or to the mucosal surface. polymers are interacted with the mucosa and referred to the mucoadhesion. The mucosal layer consists of the high molecular weighted glycoproteins that contain fucose, sialic acid. The thickness of mucin gel layer is between 50-500 micrometer in the stomach and 15150 micrometer in colon region the thickness depends on the region and adhesive properties are depends on the percentage of the glycoproteins concentartion. the systems that bind to he epithelial cell and they increased the gastric residence time in the stomach it having the self-protecting mechanisms of GI tract the goblet cells are continuously producing the mucus for protective action these systems are used for the buccal, oral, rectal, vaginal route of administration.[26] as shown in Figure 5.

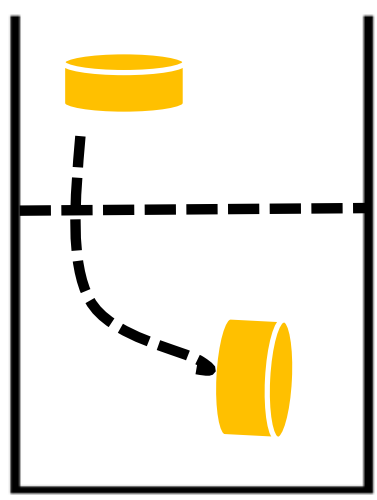

Drug + Mucoadhesive Polymer

Figure 5: Bio adhesive systems

\section{SUPERPOROUS HYDROGEL SYSTEMS}

The conventional hydrogels are a very long term process and it may take several hours to reach the equilibrium during which super porous hydrogels of pore size $>100$ micrometre swell to balance size may occur prematurely in a minute. Due to the rapid absorption of water by capillary wetting through numerous open pores interconnected Increasingly, they swell to a massive size and are intended to have sufficient mechanical strength to handle the pressure due to gastric contraction, which is attained through the co-formulation of hydrophilic particulate materials. [27] as shown in Figure 6.

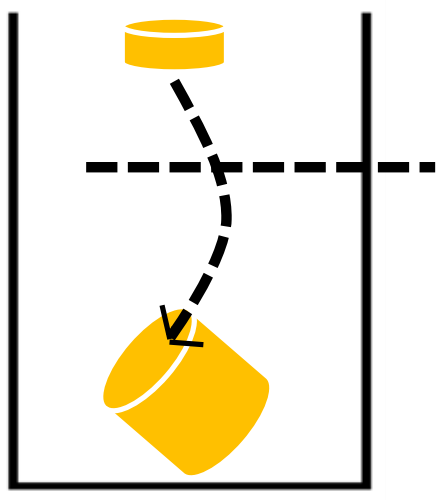

Drug + Highly Swellable Polymer

Figure 6: Superporous Hydrogel Systems

\section{MAGNETIC SYSTEM AND SELF-UNFOLDING SYSTEMS}

This consists of a small inner magnet and a magnet over the stomach position placed on the abdomen. Such systems are a treatment type containing a magnetic substance, the removal of which is prohibits by the contact with a sufficiently strong magnet applied to the body's surface in the area of the stomach. The self-unfolding systems are the ability to increase mechanically in relative size to the original dimensions. This rise stops the dose from going through the pylorus and maintains its extended stomach stay. A medication may either be included in the gastro retentive system's polymer composition, or it may be included as a separate component. The hydrogel swells in gastric juice contact. $[23,28]$

\section{NOVEL TECHNOLOGIES}

\section{Oleotec $^{\mathrm{TM}}$ and Soctec ${ }^{\mathrm{TM}}$}

OleotecTM is made specifically for drugs that demand high pharmacological doses that are not compatible with conventional forms of dosage. This system offers drugs that are primarily absorbed in or with a localized effect in the top portions of the GI tract. OleotecTM is basically a stick loaded gel that forms a continuous pattern on the layer of the stomach material. They demonstrate a long effect in the stomach. SoctecTM has been established for drugs to be kept in the stomach for an large period of time. SoctecTM is ingested easily. generally, the stomach contents are broken by peristaltic contractions and the material are rapidly ejected into the duodenum via the pylorus. SoctecTM could be held greater than nine hours in the stomach. SoctecTM releases the drug load at a fixed level during this process, enabling for ingestion in the top sections of the small intestine.it used for narrow absorption window

\section{Accordion Pill ${ }^{\mathrm{TM}}$}

Is a special gastro retentive formulation comprised of polymer. It is compressed into a standard size, compact capsule. The capsule melts when it reaches the stomach; the Accordion PillTM unfolds and is kept in the stomach for up to 12 hours under frequent diets with calories. The Accordion PillTM delivers the drug to the top portion of the gastrointestinal tract in a controlled way. Accordion PillTM is removed from the stomach; in the intestine it is wholly broken down. The Accordion PillTM can incorporate accounts for immediate and controlled release and can comprise more than one API and up to $550 \mathrm{mg}$ for high drug load. It is used for less absorption window drug from the class of III and IV as shown in Figure 7. 

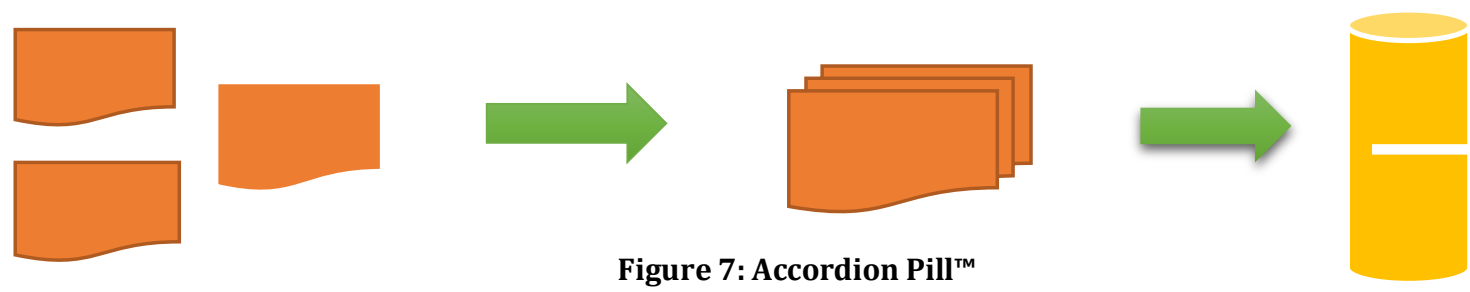

Figure 7: Accordion Pill ${ }^{\mathrm{m}}$

\section{Gastro Retentive Innovative Device (GRID)}

From this system for drug uptake only in stomach or small intestine. GRID was created to keep medicines in the stomach for a period of more than eight hours. Longer stomach availability enhances the uptake of drugs. The tablet provides a combo of immediate and prolonged drug release profiles, and enhancing patient compliance. formation of dosage form with multi-layer coating GRID retains its shape and shape during the phase of intense gastric movements in order to release medication in a controlled way. Therefore, plasma concentrations of drugs are retained for a longer period of time in the therapeutic range; hence this mode of dosage can be used as an "Once-a-day" method. Using this creative medication form, expected release of drugs can be tailored to attain an instant and slow release pairing. Retention of the medication type near the uptake site can help to minimize the dose and therefore the side effects For a lot of oral drugs. Except for instant release and some prolonged release preparation moves through the top section GI tract in about three hours after admission.as shown in Figure 8.

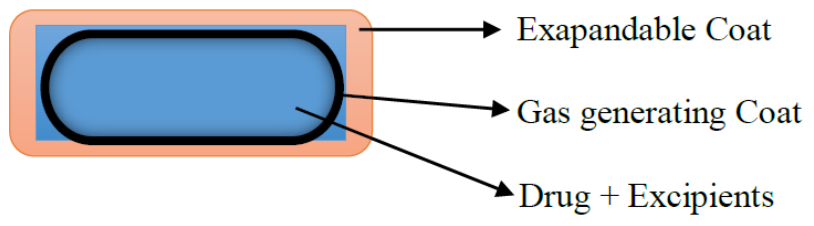

Figure 8: Gastro Retentive Innovative Device

\section{Multiple polymer hydrophilic matrix technology}

It is for the extended release of metformin hydrochloride as a gastro-retardant delivery system. The polymers are a new mixture of hydrophilic non-ionic and ionic polymers Together with the polymers, metformin hydrochloride granules are condensed into tablets in a ratio designed to provide $\mathrm{pH}$-independent drug release from the tablet. The specific release control properties of the polymer compounds enable the consistent and full release of metformin hydrochloride from the stomach to the jejunum without gastric $\mathrm{pH}$ fluctuations. When the digestive fluids interact with the tablet Metformin absorbs water hydrates and forms a swelling gelatinous matrix. The drug from the matrix takes place in a controlled environment by a cycle of dissolution of the drug and subsequent dissemination by the gel matrix. As tablet get expand they stay in stomach and show longer period of release. This show achieved clear and observable results: optimum absorption; less irritation; improved levels of plasma; and improved bioavailability

\section{Acuform ${ }^{\circledR}$ systems}

This systems are specially for targeted and controlled release action of drug The specific swelling polymers of Acuform technology allow the tablet to be kept in the stomach for about eight to ten hours. The active ingredient of the tablet is continuously administered to the upper GI tract at the optimal rate and duration during this phase. It provides the opportunity for greater effectiveness of treatment and improved tolerability of medication with the simplicity of one or two doses per day. In this technology that using drug may be in the combination. This innovation can in particular show to be an appropriate delivery method for compounds consumed in the top GI area, By means of active transport mechanisms, un-dissolved in water, irritating to stomach mucosa and they are unsuitable for bottom part of stomach it is highly efficacious when plasma level get varies this systems involved economical API that approved by FDA. For formation of dosage that uses high speed equipment

\section{Gastrointestinal permeation enhancement technology and Micropump}

A innovative approach provides for the transformation of drugs usually available injectable into oral formulations and increases the absorption of existing oral drugs.it used for bioavailability enhancer. Micropump that containing microparticles ranges from 5,000 to 10,000 each capsule or tablet.200-500 micron in size and show the release rate for extended period of time they are release in GI tract for up to $24 \mathrm{hr}$. improves the efficacy, reduced the toxicity

\section{EUDRATEC ® GRS}

It is an Evonik patent-pending product that increases nutritional supplement gastro retention. This is necessary when maintained in the stomach for a larger time for health ingredients that are most active. For this reason, EUDRATEC (B) GRS was designed to maximize the time of in the stomach EUDRATEC $®$ GRS technology ensures that ingredients are gradually released into the stomach by allowing the flattening of substance-bearing capsules on gastric fluid. EUDRAGUARD $\AA$ command and has been demonstrated in vitro in bio-related media EUDRATEC@ GRS is applicable for water-soluble agent

- Uptake at upper section

- Compatible in stomach not in intestine

The EUDRATEC ® GRS system works by incorporating vith active ingredient and the gas producing agent. The capst le is coated with EUDRAGUARD $₫$ control and other excipi 1 !nts. The outer layer is porous when enveloped in gastric icid, causing small amounts of carbon dioxide gas to escape. Release control is obtained by EUDRAGIT $₫$ NM 30 D coating the capsule[28] as shown in figure 9.

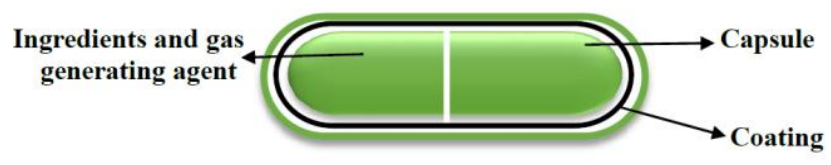

Figure 9: Eudratec GRS

\section{EXCIPIENTS USED IN FLOATING SYSTEMS}

\section{(1)Hydrocolloids-}

Hydrocolloids are the agent that having the capacity to forming the gel and. It gets swell when the gastric fluids are 
in contact. e.g- Pectin, agar, HPMC, ethylcellulose, sodium alginates.

\section{(2)Release rate accelerants-}

It is an agent that increases the rate of drug release e.glactose, mannitol

\section{(3)Release rate retardant-}

It is an agent that retards the release action of the drug by decreasing the solubility by using the substance like calcium phosphate, magnesium striate, and talc.

\section{(4)Buoyancy increasing agent-}

For increasing or enhancing the buoyancy by using the lowdensity materials like ethylcellulose

\section{(5)Effervescent agent-}

This is the agents that produce carbon dioxide by contact with the acidic medium.in floating systems, the gas generating agent like citric acid, sodium bicarbonate are used.[21]

\section{POLYMERS USED IN GASTRIC RETARDANT SYSTEMS}

There are two types of polymers are used in the formulation it may be the naturally occurring or may be synthetic or may be the semi-synthetic used for the coating action, release retardant action, synthetic polymers are may be purely synthetic or either processed from natural resources.

\section{Chitosan}

Chitosan is the natural swellable polymers. chitosan is the $\mathrm{N}$ deacetylated derivatives of chitin. chitosan that contains the primary amino group and these primary amino group are shows controlled release action, mucoadhesive properties, in -situ gelation, enhanced the permeability chitosan having the non-toxic, biodegradable, biocompatible polymer, use of the chitosan is for oral extended-release tablet it can be either by granulation, or simply direct compression method.[29]
Sheth et.al, formulate and evaluate microspheres of levetiracetam by using chitosan about $0.5-8 \%$ of Chitosan is used to arrange microspheres demonstrating continued release of drugs and floating for $>8$ hours[30]

Subhojit et.al,(2012)Develope and analyses a floating tablet of cefixime trihydrate presence of the chitosan and they show excellent results on the hardness, friability, thickness, weight variation and also sows the good results on drug release and floating time.[31]

Preparation of floated tablet of Tapentadol HCL by using chitosan they show the release retardant action on the drug and also effect on the drug release, floating time, and other post-compression evaluation and about $28 \%$ chitosan shows the sustained release action $[32,33]$

\section{HPMC}

HPMC contains methoxy and hydrolpropoxy groups having the molecular weight 10000-1500000 Dalton. it is dissolve in the water they forms colloidal solution. Certain grades are soluble in acetone.

It is acts as a bioadhesive, coating activity, controlled release capacity, emulsifying agent, thickening agent, they are widely used in the oral, opthlmic, nasal, and topical formulation or oral preparation, they are used for the tablet binder, coating solution for extended-release of the tablet for release retardant action the high viscosity grade is used. The HPMC grade involved in the liquid preparation as a category of suspending and viscosity increasing agent of concentration $0.25-5.0 \%$ for the film coating about $2-2.0 \%$ of polymer are used they are compatible at $\mathrm{pH} 3-11$ and the gelation temperature as $50-90^{\circ} \mathrm{C}$ depending on grade and its amount to be used there are three different HPMC grade as E5, E50, and $\mathrm{K} 4 \mathrm{M}[34,35]$ formulate the gastro-retentive controlled released tablet by using verapamil HCL as a model drug using polymers such as HPMC and xantham gum 3:2ratio and they show $95.39 \%$ drug release in $24 \mathrm{hr}[36,37]$

Table 1: Various grade HPMC

\begin{tabular}{|l|l|l|l|}
\hline HPMC Grade & Viscosity 2\% mPa.sa & Molecular. Weight kDa & Release mechanism \\
\hline HPMCK100M & 100,000 & 1150 & Swelling/Diffusion \\
\hline HPMCK15M & 18,000 & 750 & Swelling/Diffusion \\
\hline HPMCK4M & 4000 & 500 & Swelling/Diffusion/Erosion \\
\hline HPMCK100LV & 100 & 120 & Erosion \\
\hline
\end{tabular}

\section{Eudragit}

Eudragit is amorphous. eudragit obtained from polymerization of acrylic acid and methacrylic acids are mostly used for coating materials and taste-masking agents in oral dosage forms by spray atomization techniques. and there glass transition temperature is $90-150^{\circ} \mathrm{C}$.it is nonbiodegradable, non-absorbent, and non -toxic in nature are of the two grades of the polymer as L and S. L is dissolved at pH6 for coating grade S dissolved at $\mathrm{pH} 7$ used for colon targeted systems. RS and RL containing a quaternary amino group and they used for sustained release. eudragit $\mathrm{E}$ unable to dissolved at pH 5 and they prohibits the initiation of drugs at saliva eudragit are in the various forms such as dispersion, organic solution, granular, powder. According to grade we have discussed there solubility, description, and there application.

Punitha et al,.(2010) They prepared floating microsphere by using ranitidine HCL as a drug and using two polymers such as HPMC and Eudragit grade E-100 with various ratio by using these and they achieved an extended-release in GI tract results as increased the absorption and enhanced the bioavailability.

Eudragit RL100 floated faster than Eudragit RS100[38, 39] 
Table 2: Various grade of eudragit

\begin{tabular}{|l|l|l|}
\hline Immediate Release & Colon Targeting & Delayed Release \\
\hline E 100 & FS 100 & L 100 \\
\hline E PO & S 100 & L 100-55 \\
\hline E 12,5 & - & L 12,5 \\
\hline
\end{tabular}

\section{Ethylcellulose}

Ethylcellulose is derived from the cellulose-containing the hydroxyl groups used for the microencapsulation, white in color, odourless, tasteless with having melting point 240$255^{\circ} \mathrm{C}$ it is non-biodegradable, in nature, non-toxic, nonirritant they having three different grades as $\mathrm{K}, \mathrm{N}$ and $\mathrm{T}$ type in which $\mathrm{K}$ type containing $44.47 .9 \%$ of ethoxy group, $\mathrm{N}$ containing 48-49.5\% and T type containing 49.6-51\%.

Pande et al,. prepared the floating microspheres using cefpodoxime proxetil as a model drug and using two polymers such as ethylcellulose and HPMC they taking with varying concentrations and from that concluded as EC concentration also increases the efficacy of trapping. [40]

S. Chandran et al,. Formulate matrix tablet of ibuprofen using rate-controlling polymers such as ethylcellulose to reduces the gastric irritants and prohibites the initiation of drug in the acidic area of stomach $14-16 \mathrm{Hr}$ [41]

\section{Guar gum}

It is obtained from natural sources from the species of Cyamopsis tetragonolobus it is non-ionic in nature[42]

Guar gum containing the hydroxyl groups it is polysaccharides having molecular weight 50,000$8,000,000$.If they are dissolved in water they show the gelling properties and show the sustained release action. [43, 44]

Kanwar et al.,(2015) formulate the pregabalin floating tablet using a different concentration of the natural polymers and they show the higher floating time grether than $24 \mathrm{Hr}$ and show extended-release action.[45]

\section{Xanthan gum}

It is heteropolysaccharides in nature getted from aerobic fermented carbohydrates from species of Xanthomonas compestris it contains glucose, glucuronic acid, and mannose. For formulation to increase or decreases the drug release it is not used or shows the sustained release of drug in the zero-order kinetics.[46, 47]

Formulate and evaluate the GRDDS tablet of domperidone by using xantham gum and guar gum and they show good swelling properties and show drug activity for greater than $12 \mathrm{Hr} .[48]$

Formulate and evaluate gastro retentive norfloxacin floating tablet for increasing gastric residence time and enhancing bioavailability. For controlled release action using polymer HPMC, and xanthan gum increased the buoyancy behaviours.[49]

\section{Pectin}

Pectin is a biopolymer they have the capacity to forming the gel. pectin obtained from the cell wall of the plant. It is bioadhesive in nature.[50] Pectin shows sustained release action but also shows a drug carrier in targeting therapy [51, 52]

Satheesh babu et al,.(2016) formulate the calcium pectinate gel beads using famotidine as a model drug using low methoxy pectin and HPMC and thus they show sustained release action

Table 3: Polymers in different dosage form.

\begin{tabular}{|l|l|l|}
\hline Sr.No. & Dosage Form & Polymer used \\
\hline 1 & Tablets & $\begin{array}{l}\text { Xanthan Gum, Karaya Gum, Guar Gum, Carrageenan, Hydroxypropyl } \\
\text { Methylcellulose (HPMC K4M, HPMC K100M) HPMC E15LV, HPMC E50LV, HPMC } \\
\text { K100LV, Polyvinyl Pyrrolidone (PVP K30) HPMC K15M, Carbopol, Sodium } \\
\text { Carboxymethyl Cellulose, PVP K30 Psyllium Husk, Crospovidone }\end{array}$ \\
\hline 2 & Microspheres & Ethylcellulose, Eudragit RL100, Cellulose Acetate \\
\hline 3 & Matrix Tablet & HPMC K4M, HPMC K15M, HPMC K100K, Ethyl Cellulose. \\
\hline 4 & Superporous Hydrogel & HPMC, Carbopol 934P,Ethyl Cellulose, Chitosan, Sodium Carboxymethyl Cellulose \\
\hline 5 & Microballoons & HPMC K4M, Ethyl Cellulose \\
\hline
\end{tabular}

\section{CONCLUSION:}

Gastro retentive is the most favourable approach for delivery of the specific quality and quantity of the drug for some long term disease treatments on these many approaches has been developed in these delivery systems for the site-specific and disease-specific action of the molecules in these technologies using the many polymeric condition that according to the site-specificity and their effectiveness. According to type of systems and there dosage forms the polymer selection and there concentration is to be different. If the high-density polymer used then the technology or approaches in GRDDS is change. Many synthetic, non-synthetic, and naturally occurring intermediates are to be used. Many of the formulation are involved in market according to the systems and dosage form which are they are in may be tablet, beads, gel, capsule forms.

\section{REFERENCES:}

1.Patil H, Tiwari RV, Repka MA. advancements in bioadhesive floating drug delivery systems: A mini-review. J Drug Deliv Sci Technology 2016; 31:65-71.

2.GhoshD.Ghosh R. Floating drug delivery systems:review. Int J Pharm Med 2013;35:10-15.

4.Streubel A, Siepmann J, Bodmeier R. Drug delivery to gastroretentive technologies. Currt opini in pharmacology. 2006; 6(5):501-8.

5.Singh B et al. QbD-enabled development of novel stimuliresponsive gastroretentive systems of acyclovir for improved patient 
compliance and biopharmaceutical performance. AAPS PharmSciTech. 2016; 17(2):454-65.

6.Malpure PS,Chavan BR. Gastroretentive Drug Delivery SystemS. wjpps. 2019; 8(3):506-28.

7.Tomar A, Upadhyay A, Gupta S, Kumar S. An Overview on Gastroretentive Drug Delivery System: Current Approaches and Advancements. Curnt Research in Pharma Sci 2019; 9(01)12-6.

8.Khanvilkar K, Donovan MD, Flanagan DR. Drug transfer through mucus. Adv drug delivery reviews. 2001; 48(2-3):173-93.

9.Aspden TJ et al. Chitosan as a nasal delivery system. Journal of pharmaceutical sciences 1997; 86(4):509-13.

10.Garg R. Progress in controlled gastroretentive delivery systems. Tropical jrnal of pharma research 2008; 7(3):1055-66.

11.Gunda RK. Formulation Development and Evaluation of Gastro Retentive Drug Delivery Systems-A Review. Journal of Pharmacy Research 2017; 8(1):11-20.

12. More S, Gavali K, Doke O, Kasgawadek P. Gastroretentive Drug Delivery System. Journal of Drug Delivery and Therapeutics 2018; 8(4):24-35.

13.Kumar M. Approaches and Recent Patents on Gastroretentive Drug Delivery Systems. Recent patents on drug delivery \& formulation 2018; 12(2):84-92.

14.Badoni A. Review on gastro retentive drug delivery system. The pharma innovation. 2012; 1(8, Part A):32.

15.Tripathi P, Ubaidulla U, Khar RK. Floating drug delivery system. IJRDPL. 2012; 1:1-10.

16.Kim S et al. Preparation and evaluation of non-effervescent gastroretentive tablets containing pregabalin. International journal of pharmaceutics. 2018; 550(1-2):160-9.

17.Meka VS, Li CE, Sheshala R. Design effervescent floating drug delivery system of theophylline using response surface methodology. Acta Pharma. 2016; 66(1):35-51.

18.Thapa P, Jeong S. Effects of formulation and process variables on gastroretentive floating tablets. Pharmaceutics. 2018;10(3):161.

19.Kriangkrai $\mathrm{W}$ et al. Impact of anti-tacking agents on properties of gas-entrapped membrane and effervescent floating tablets. AAPS PharmSciTech. 2014; 15(6):1357-69.

20. Parajapati S, Maurya S, Das M, Tilak VK, Verma KK, Dhakar RC. Potential Application of Dendrimers in Drug Delivery: A Concise Review and Update. Journal of Drug Delivery and Therapeutics, 2016; 6(2):71-88

21.Tripathi J, Thapa P. Review on gastroretentive drug delivery systems. Pharmaceutics. 2019; 11(4):193.

22.Shah S, Patel J, Patel N. floating drug delivery system: A review. Int J Pharm Tech Res. 2009; 1(3):623-33.

23.Bardonnet P, Faivre V. Gastroretentive dosage forms: Overview Helicobacter pylori. Journal of controlled release. 2006; 111(1-2):118.

24.Deshpande AA, Shah NH. Development of a novel controlledrelease system for gastric retention. Pharmaceutical research. 1997; 14(6):815-9.

25.Singh B, Chakkal SK, Ahuja N. Formulation and optimization of controlled release mucoadhesive tablets. AAPS PharmSciTech. 2006; 7(1):E19-E28.

26.Nayak AK, Malakar J. Gastroretentive drug delivery technologies. Journal of Pharmaceutical Education \& Research. 2010; 1(2).

27.Nayak AK, Das B, Maji R. Gastroretentive systems of ofloxacin. Saudi Pharmaceutical Journal. 2013; 21(1):113-7.

28.Chudiwal V, Shahi S, Chudiwal S, Ahale D. Innovative Technologies for Gastro-Retentive. Asin Jrnl of Pharma Edu and Research. 2017; 6(4):22-8.
29.Kas HS. Chitosan: In microparticulate systems. Journal of microencapsulation. 1997; 14(6):689-711.

30.Kaushik AY, Tiwari AK. Role of excipients and polymeric advancements in floating drug delivery systems. Int jrnl of pharma invest. 2015; 5(1):1.

31.Bandana S, Jovita K, Manisha P. Formulation floating microspheres of famotidine. Metabolism. 2010; 3:4.

32.Kumar MNR. A review of chitin and chitosan applications. 2000; 46(1):1-27.

33.Ali A, Shahid MA, Hossain MD, Islam MN. Antibacterial bi-layered polyvinyl alcohol (PVA)-chitosan blend nanofibrous mat loaded with Azadirachta indica (neem) extract. International journal of biological macromolecules. 2019; 138:13-20.

34.Sungthongjeen S, Sriamornsak P. Design of floating HPMC matrix tablets. Advanced Materials Research; 2011: Trans Tech Publ.

35.Zema L, Maroni A. Different HPMC viscosity grades as coating agents for an oral time and/or site-controlled delivery system. Journal of pharmaceutical sciences. 2007; 96(6):1527-36.

36.Karthikeyan D, Karthikeyan M. Effect of different viscosity grades of HPMC on drug release profile. J Pharm Res. 2008; 1(1):23-8.

37.Roy H, Brahma CK. Formulation and design of sustained release matrix tablets of metformin hydrochloride. International Journal of Applied and Basic Medical Research. 2013; 3(1):55.

38.Thakral S, Thakral NK, Majumdar DK. Eudragit $\AA$ : a technology evaluation. Expert opin on drug delivery. 2013; 10(1):131-49.

39.Nikam VK, Kotade K. Eudragit a versatile polymer: a review. Pharmacologyonline. 2011; 1:152-64.

40.Pande AV, Vaidya PD. In vitro and in vivo evaluation of floating microspheres of cefpodoxime proxetil. Int J Pharm Biomed Res. 2010;1(4):122-8.

41.Chandran S, Asghar LF. Design and evaluation of ethyl cellulose based matrix tablets of ibuprofen . Indian journal of pharmaceutical sciences. 2008; 70(5):596.

42.Krishnaiah Y, Karthikeyan R. A three-layer guar gum matrix tablet for oral controlled delivery of highly soluble metoprolol tartrate. Int jrnal of pharma. 2002; 241(2):353-66.

43.Sharma G, Sharma S, Kumar A. Guar gum review. Carbohydrate polymers. 2018; 199:534-45.

44.Kumar SA, Vivek D, Vandana A. polymers used in floating drug delivery system. Journal of Pharma and Sci Innovation. 2012; 1(3):11-5.

45.Kanwar N, Kumar R. Preparation of floating tablets of pregabalin. Drug development and industrial pharmacy. 2016; 42(4):654-60.

46.Prakash U, Singh L, Sharma V. Role of xanthan gum in gastroretentive drug delivery system: An overview. Int Res J Pharm. 2013; 4(4):35.

47.Panda S, Sailada NS, Devi B, Pattnaik S, Maharana L. Design of Floating Drug Delivery Systems: An Update on Polymeric Advancements with Special Reference from Natural Origin.

48.Gandhi A, Verma S, Imam SS, Vyas M. A Review On Techniques For Grafting Of Natural Polymers And Their Applications. Plant Archives. 2019; 19(2):972-8.

49.Bomma R, Naidu RS.gastroretentive norfloxacin floating tablets. Acta pharmaceutica. 2009; 59(2):211-21.

50.Sriamornsak P. pectin in oral drug delivery. Expert opinion on drug delivery. 2011; 8(8):1009-23.

51.Thakur BR, Singh RK. pectin-a review. Critical Reviews in Food Science \& Nutrition. 1997; 37(1):47-73.

52.Sundar Raj A, Rubila S. A review on pectin. Scientific reports. 2012; 1:550-1. 